MEMÓRIA

\title{
Um historiador que nunca dorme: os "anos vermelhos" de Luiz Alberto Moniz Bandeira
}

\author{
A Historian who Never Sleeps: \\ The "Red Years" of Luiz Alberto Moniz Bandeira \\ Ana Vitoria Sampaio Castanheira Rocha ${ }^{\star 1}$
}

As gerações nos hão-de suceder,

mas enquanto houver na terra luz, mesmo morrendo, assim vamos viver

Moniz Bandeira, 2000

Em 10 de novembro de 2017 faleceu Luiz Alberto de Vianna Moniz Bandeira, professor titular aposentado da Universidade de Brasília. As narrativas biográficas sobre Moniz Bandeira contam a história de um intelectual incansável, perfeccionista e generoso, que teve com a História, em particular, e com as Ciências Humanas, em geral, um compromisso de vida. Vencedor do prêmio Juca Pato em 2005, e indicado ao Prêmio Nobel pela União Brasileira de Escritores em 2015, a obra de Moniz Bandeira deixou uma marca indelével na historiografia brasileira. Sua ampla e multifacetada produção permite que continue dialogando com sucessivas gerações, fazendo ecoar sua voz por um tempo que ultrapassa sua existência física.

Sinceramente, devo admitir que escrevo estas palavras com a pena da pessoalidade, que mesmo disfarçada, acabaria acusada nas entrelinhas do texto. Tive o privilégio de conviver, mesmo que a distância (por Skype e e-mail), com esse memorável intelectual e, ao mesmo tempo, acompanhar a reescrita de uma obra - O Ano Vermelho: a Revolução Russa e seus reflexos no Brasil. Os diálogos entre mim, historiadora jovem, e meu mestre, nascido no ano de 1935, deixaram profundas lições acerca do fazer historiográfico e da escrita da história, sobretudo em relação à obra em epígrafe. Nas palavras de outro saudoso historiador, Manoel Luiz Salgado Guimarães, que fez importantes reflexões

\footnotetext{
* Universidade de Brasília, Programa de Pós-Graduação em História. Brasília, DF, Brasil. avrochagrrl@ gmail.com
} 
acerca da historiografia, enxergo Moniz Bandeira em seu incômodo e intenso desejo de aprimorar o livro publicado em 1967, escrito pouco tempo após o exílio vivido no Uruguai. Segundo Guimarães, a escrita da História é um exercício de domesticação do passado, necessário em razão das novas demandas produzidas pelo tempo presente (Guimarães, 2006, p.47). Moniz Bandeira era constantemente impulsionado por essas novas questões, transformando sua obra em objeto de permanente revisão e, dada a intensidade do impulso, de verdadeira recriação.

Graduado em Direito pela Faculdade Brasileira de Ciências Jurídicas (1960) e Doutor em Ciência Política pela Universidade de São Paulo (1982), Moniz Bandeira adentrou o campo da História com acentuada curiosidade. Dedicando-se ao saber durante toda a vida, o intelectual não hesitou em tentar compreender os movimentos do tempo em suas continuidades e rupturas, bem como as (re)leituras e (re)escritas historiográficas produtoras de sentidos para a vida humana. Destacando-se por suas contribuições em História das Relações Internacionais, Moniz Bandeira se debruçou sobre o papel do Brasil na Bacia do Prata nos tempos coloniais e imperiais (2012); a Revolução Cubana e o que ela representou para a América Latina (1998); bem como a presença imperial norte-americana no Brasil e no mundo (2007). Articulando passado, presente e futuro, o historiador recorria à escrita da História na ânsia de expurgar, ou ao menos apaziguar, os demônios dos conflitos políticos e sociais que testemunhava e, muitas vezes, vivenciava, com graves consequências à sua existência.

Iniciou sua vida profissional como jornalista no Diário da Bahia em 1951, passando pelas redações do Diário da Noite, Jornal do Commercio, Correio da Manhã e Diário de Notícias. Sua militância política foi notável, tendo na juventude ajudado a organizar a Juventude Socialista na Bahia e no Rio de Janeiro. Filiado ao Partido Socialista Brasileiro (PSB) nos anos 1950, foi também assessor do deputado Sérgio Magalhães do Partido Trabalhista Brasileiro (PTB) (Ferreira; Silva Júnior, 2010, p.6). Com o golpe de 1964, Moniz Bandeira exilou-se no Uruguai com o presidente deposto, João Goulart, e lá ficou até 1965. De volta ao Brasil, viveu na clandestinidade e foi preso pela Ditadura Militar em dois momentos distintos, de 1969 a 1970 e depois em 1973 (Cult, s.d.).

Livre-pensador acima de tudo, Moniz Bandeira deixou valiosas lições por meio de sua última trilogia, ${ }^{2}$ sobretudo no campo da História do Tempo Presente. Os acontecimentos políticos do Brasil o afetavam profundamente, como ficou inscrito em correspondência privada trocada entre nós em 2016, pouco antes da queda da presidenta Dilma Rousseff: "a situação do Brasil é realmente 
muito, muito, muito, triste". ${ }^{3}$ Não é nenhum segredo que, para ele, Rousseff foi vítima de um golpe, que começou a denunciar ainda no ano de 2013 durante as Jornadas de Junho, percebendo naquelas manifestações os contornos da política de regime change levada a efeito em outros lugares como Ucrânia e Egito. Moniz Bandeira mudou-se para a Alemanha com a esposa Margot e o filho Egas ainda na década de 1990, mas jamais perdeu o vínculo pátrio, sendo, antes de tudo, um nacionalista apaixonado pelo Brasil e seu povo.

Era perceptível, para qualquer pessoa que o tenha conhecido, que sua relação com a História era movida pelos combustíveis da curiosidade e do desconforto com as assimetrias, fossem elas entre os atores sociais de uma nação ou entre os Estados empenhados na luta por espaços de poder e influência na arena internacional. Moniz Bandeira era um historiador livre e suficientemente qualificado para não se prender a linhas teórico-metodológicas rígidas, sendo capaz de conciliar elementos analíticos do marxismo dialético com propostas da Nova História Política, bem como as novas metodologias da História das Relações Internacionais. Filho e herdeiro de um zeitgeist acelerado, conflitante e suscetível às paixões, o intelectual deixava o caminho livre para a História inscrever-se em sua vida, da mesma forma como nela se inscreveu por meio do fazer historiográfico. Sua obra nunca deixou de dialogar com o presente e o futuro, diálogo que Moniz Bandeira conseguiu estabelecer por meio de pontes construídas com contornos reflexivos, elaboradas para e na consciência histórica (Rüsen, 2015, p.219).

A primeira edição de $O$ Ano Vermelho foi escrita com a colaboração de Clóvis Melo e Aristélio T. de Andrade, contando com prefácio de Nelson Werneck Sodré. Este deixou algumas impressões pessoais sobre o projeto, assumindo, a priori, tê-lo enxergado com desconfiança devido ao "exíguo prazo" que poderia comprometer a qualidade da pesquisa. Havia, também, a pressa editorial em publicar o livro para aproveitar as comemorações pelo aniversário dos 50 anos da Revolução Socialista Soviética (Sodré, 1967, p.1). Apesar dos elogios dados, então, pelo próprio Sodré e por outros intelectuais renomados, como Darcy Ribeiro, meio século após sua publicação, e cem anos após a Revolução Russa, Moniz Bandeira considerava $O$ Ano Vermelho uma obra incompleta e, por isso, digna de revisão. Com 80 anos de idade o historiador se lançou ao desafio de escrever outro livro, considerado por ele um trabalho inteiramente novo.

É possível reconhecer no autor uma relação de leitor dos próprios textos (Chartier, 2002, p.26), que se rendeu a sentidos não engessados produzidos por certos incômodos na medida em que as transformações, proporcionadas 
pelo tempo, pelas novas leituras, pelas descobertas descortinadas por um grande número de pesquisas acadêmicas, apresentavam novos problemas e possibilidades aos seus objetos de análise. Tendo isso em vista, fica mais fácil compreender as razões que levaram suas obras a serem tantas vezes reeditadas. Reedições estas que não se resumiram a uma mera reimpressão, mas resultaram em outros insights, elaborações, conclusões. Por diversas vezes, quando mencionávamos a revisita ${ }^{4}$ a algum livro de sua autoria, ele perguntava de qual edição se tratava, e, se fosse mais antiga, respondia: "joga fora! Isso não serve mais de nada!”. Por sorte não seguimos seus conselhos, pois essas leituras possibilitaram conhecer o dinamismo de seus modos de produzir, visto por muitos como um perfeccionismo exacerbado. Na realidade, esse perfeccionismo fazia parte de um ininterrupto exercício de compreensão do mundo que o cercava. Um mundo impiedoso, que não cessa suas transmutações para ser compreendido.

$\mathrm{Na}$ mais recente edição de $O$ Ano Vermelho o autor se deslocou para um tempo ainda mais longínquo, compreendendo um período de longa duração. A economia brasileira do final do período colonial e durante o Império, as revoltas escravas, a Lei Áurea e suas consequências econômicas, bem como a imigração europeia, foram temas explorados com profundidade pelo historiador. O questionamento ao episódio do surgimento da República como "proclamação" também está presente. Para Moniz Bandeira, tratou-se de um golpe republicano à Monarquia dos Bragança, questão largamente explorada pela pena do intelectual.

Eventos como as insurreições políticas do Oitocentos, os conflitos entre os diferentes grupos humanos e as tensões raciais e sociais foram articulados à luta de classes em solo russo e ao rude jogo de poder que se desenrolava na cena internacional. A formação de uma classe operária brasileira, largamente fomentada pela entrada massiva de imigrantes europeus no período que se estende do final do século XIX ao início do XX, bem como pelo fim do regime escravista em 1888, fez sua aparição como elemento catalisador dos conflitos e das profundas contradições sociais nas pioneiras greves empreendidas no alvorecer dos anos 1900. Da mesma forma, as repercussões na imprensa brasileira sobre a Revolução de 1917 foram postas em uma teia de acontecimentos que se interligam e dialogam com as experiências cotidianas dos povos residentes nas terras "d'Além-Mar".

Além das críticas às elites políticas republicanas, Moniz Bandeira revisitou a história do anarquismo no Brasil, profundamente plural e de intensa atividade no início do século XX. O autor identificou a origem do Partido 
Comunista do Brasil (PCB), de 1922, no movimento anarquista: ao invés de surgir como uma dissidência da social-democracia, ainda muito inexpressiva nos movimentos operários dos anos 1920, o PCB teria sido fundado por seguidores de Bakunin e Kropotkin que, no país, passaram a se reconhecer como comunistas (Moniz Bandeira, 2017, p.436).

Movido pelo apreço e compromisso com a História e com a própria produção bibliográfica, Moniz Bandeira presenteou o público brasileiro com essa nova obra, lançada poucos dias antes de sua morte. Em formato de edição comemorativa pelos 50 anos da primeira edição, bem como pelo centenário da Revolução Russa, o "historiador que nunca dorme" imprimiu nos anais da historiografia brasileira uma vida, como intelectual e ativo militante, digna de ser rememorada e celebrada como inspiração para a construção do eterno sonho humano de igualdade, tão bem descrito por sua pena nos anos vermelhos que se foram, e tão bem imaginado nos anos vermelhos como promessa do porvir, no qual nunca deixou de acreditar.

\section{REFERÊNCIAS}

CHARTIER, Roger. A História Cultural: entre práticas e representações. Trad. Maria Manuela Galhardo. 2.ed. Lisboa: Difel, 2002.

CULT. Entrevista Moniz Bandeira: a teoria e a práxis se realimentam mutuamente e se corrigem. (s.d.). Disponível em: www.revistacult.uol.com.br/home/entrevista-moniz-bandeira; Acesso em: 22 dez. 2017.

FERREIRA, Marieta de M.; SILVA JÚNIOR, Lourival M. Luiz Alberto de Vianna Moniz Bandeira (depoimento, 2003). Rio de Janeiro: CPDOC, 2010.

GUIMARÃES, Manoel Luiz S. Escrever a História, domesticar o passado. In: LOPES, Antonio H.; PESAVENTO, Sandra J.; VELLOSO, Monica P. (Org.) História e linguagens: texto, imagem, oralidade e representações. Rio de Janeiro: Viveiros de Castro Ed., 2006. p.45-57.

MONIZ BANDEIRA, Luiz Alberto de V. A Desordem Mundial - o espectro da dominação total: guerras por procuração, terror, caos e catástrofes humanitárias. Rio de Janeiro: Civilização Brasileira, 2016.

. A Expansão do Brasil e a formação dos Estados na Bacia do Prata: Argentina, Uruguai e Paraguai (Da colonização à Guerra da Tríplice Aliança). 4.ed. Rio de Janeiro: Civilização Brasileira, 2012.

A Segunda Guerra Fria: geopolítica e dimensão estratégica dos Estados Unidos - das rebeliões na Eurásia à África do Norte e Oriente Médio. 2.ed. Rio de Janeiro: Civilização Brasileira, 2014. 
MONIZ BANDEIRA, Luiz Alberto de V. De Martí a Fidel: a Revolução Cubana e a América Latina. Rio de Janeiro: Civilização Brasileira, 1998.

. Formação do Império Americano: da guerra contra a Espanha à guerra no Iraque. 4.ed. Rio de Janeiro: Civilização Brasileira, 2014.

. O Ano Vermelho: a Revolução Russa e seus reflexos no Brasil. 4.ed. revista e ampliada. Rio de Janeiro: Civilização Brasileira, 2017.

. Presença dos Estados Unidos no Brasil: dois séculos de História. 4.ed. Rio de Janeiro: Civilização Brasileira, 2007.

. Uma coroa para Margot. 2000. Disponível em: http://www.jornaldepoesia. jor.br/monizbandeira1.html; Acesso em: 20 mar. 2018.

RÜSEN, Jörn. Teoria da História: uma teoria da história como ciência. Trad. Estevão C. de R. Martins. Curitiba: Ed. UFPR, 2015.

SODRÉ, Nelson Werneck. Uma contribuição importante. In: ANDRADE, Aristélio T. de; MELO, Clovis; MONIZ BANDEIRA, Luiz Alberto. O Ano Vermelho: a Revolução Russa e seus reflexos no Brasil. Rio de Janeiro: Civilização Brasileira, 1967. p.1-4.

\section{NOTAS}

${ }^{1}$ Doutoranda em História na Universidade de Brasília (UnB), bolsista do CNPq.

${ }^{2}$ Formação do Império Americano: da guerra contra a Espanha à guerra no Iraque (2014); A Segunda Guerra Fria: geopolítica e dimensão estratégica dos Estados Unidos - das rebeliões na Eurásia à África do Norte e Oriente Médio (2014); A Desordem Mundial - o espectro da dominação total: guerras por procuração, terror, caos e catástrofes humanitárias (2016).

${ }^{3}$ Correspondência (por e-mail) trocada nos dias 15 e 16 de abril de 2016.

${ }^{4}$ Eu e o Dr. Luiz Cláudio Machado dos Santos, professor de História Moderna da Universidade Federal do Pará (UFPA, campus Bragança).

Artigo recebido em 10 de fevereiro de 2018.

Aprovado em 20 de março de 2018.

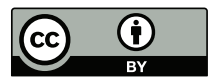

